\title{
In Situ AFM Imaging of Platinum Electrode Surface during Oxidation-Reduction Cycles in Alkaline Electrolyte
}

\author{
Xin Deng, ${ }^{\dagger}$ Federica Galli, ${ }^{\ddagger}$ and Marc T.M. Koper* ${ }^{* \dagger}$ \\ ${ }^{\dagger}$ Leiden Institute of Chemistry, Leiden University, P. O. Box 9502, 2300 RA Leiden, The Netherlands \\ ${ }^{\ddagger}$ Huygens-Kamerlingh Onnes Laboratory, Leiden University, Niels Bohrweg 2, 2333 CA Leiden, The Netherlands
}

\section{Supporting Information}

\begin{abstract}
The development of energy conversion systems depends strongly on our fundamental understanding of the electrochemical interface of the electrocatalyst. Here, we study the changes in the surface morphology of a platinum polycrystalline electrode during oxidation-reduction cycles in a wide potential window $(0.05-2.0 \mathrm{~V})$ in sodium hydroxide by in situ atomic force microscopy. Platinum nanoparticles are observed on the surface after cycling due to the redeposition of dissolved platinum ions. The influence of scan rate on platinum redeposition is studied by applying asymmetric potential sweep programs. The negative-going scan rate is the key factor here, as it controls the reduction of platinum oxide, as well as the redeposition of platinum. Moreover, it is found that chloride ions in the electrolyte impede the redeposition by complexing with platinum. This investigation enables us to reveal the surface roughening processes on platinum electrode in alkaline electrolyte and assists in understanding the fundamentals of the stability of platinum-containing energy conversion systems.
\end{abstract}

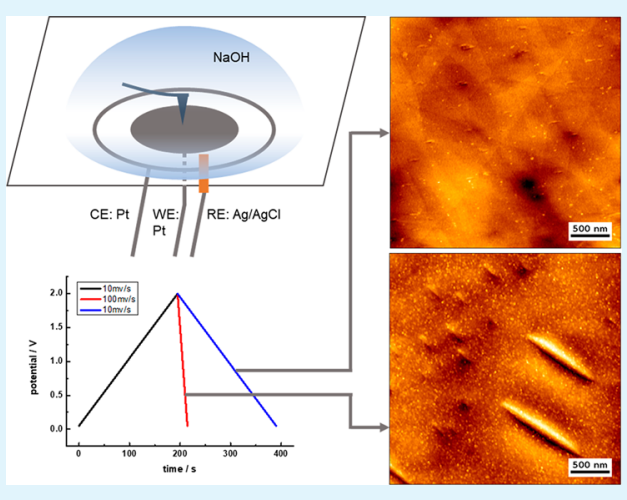

KEYWORDS: platinum, oxidation-reduction cycles, in situ AFM, platinum nanoparticles, alkaline electrolyte, platinum complexation

\section{INTRODUCTION}

The electrochemical stability of platinum plays a vital role in determining the efficiency and lifetime of various energy conversion devices, in particular fuel cells and water electrolyzers, which employ platinum as electrocatalyst. Nanoparticulate $\mathrm{Pt}$ is normally utilized to reduce the cost by decreasing the $\mathrm{Pt}$ loading. However, the dissolution and coarsening of platinum nanoparticles and the corresponding loss in electrochemical active surface area lead to the degradation of fuel cells and elecrolyzers. ${ }^{1}$ Strategies have been proposed to prevent or diminish the degradation of platinum either by enhancing the $\mathrm{Pt}$-carbon interaction or by alloying platinum with other metals. ${ }^{2,3}$ Furthermore, it is of significant importance to investigate the underlying mechanism for the electrochemical processes at Pt electrodes during potential cycling. It is generally accepted that the oxidation of polycrystalline platinum commences by the formation of a surface layer of chemisorbed hydroxide and/or oxygen in the $0.85-1.15 \mathrm{~V}$ (vs RHE) range. ${ }^{4}$ In the $1.15-1.4 \mathrm{~V}$ potential range, a place-exchange process occurs, in which surface platinum atoms change their position with the oxygen derived from the oxidation of water. ${ }^{5}$ When the applied potential is higher than $1.8 \mathrm{~V}$, it has been suggested that a new phase of oxide $\left(\mathrm{PtO}_{2}\right)$ starts to grow on top of $\mathrm{PtO}$, without reaching any limiting thickness. ${ }^{6}$ In the reduction process, $\mathrm{PtO}_{2}$ reduces at a lower potential than that of $\mathrm{PtO}$, which brings irreversibility to the system. ${ }^{7}$ For a $\mathrm{Pt}(111)$ electrode, the situation appears to be slightly simpler: a $\mathrm{Pt}-\mathrm{O}$ surface layer forms at ca. $1.1 \mathrm{~V}$, followed by the formation of an $\alpha-\mathrm{PtO}_{2}$ phase at $1.25 \mathrm{~V} .{ }^{8}$ According to density functional theory (DFT) calculations, this initial oxide is rather a suspended oxide than one in which actual place exchange has taken place. ${ }^{9}$ After reduction of the oxide, platinum adatoms and vacancies are created on the surface, as well as platinum dissolved in the electrolyte, leading to surface roughening. ${ }^{10}$ Extensive morphological changes of the platinum surface happen as a result of prolonged oxidation-reduction treatments, as for instance documented in the work by Arvia et al. ${ }^{11,12}$

The dissolution and surface roughening of polycrystalline platinum in acidic electrolyte due to oxidation and reduction cycles has been studied extensively. Mayrhofer et al. ${ }^{13-18}$ used online inductively coupled plasma mass spectrometry (ICPMS) combined with an electrochemical scanning flow cell to monitor the dissolution of platinum during electrochemical cycling. Two different dissolution phases were detected during cycling: dissolution during the positive-going scan, and dissolution during the negative-going scan, respectively. The dissolution during the negative-going scan makes the biggest contribution to the overall platinum dissolution and starts when the upper potential limit exceeds $1.15 \mathrm{~V}$. The onset

Received: September 16, 2019

Accepted: December 3, 2019

Published: December 3, 2019 
potential for platinum dissolution depends strongly on the crystalline orientation of the surface, increasing in the order of $\operatorname{Pt}(111)<\operatorname{Pt}(100)<\operatorname{Pt}(110) .{ }^{19}$ The morphology of the platinum surface during potential excursion has been characterized by utilizing scanning probe microscopy, either scanning tunneling microscopy (STM) or atomic force microscopy (AFM). The surface roughening phenomenon of platinum single crystals after multiple oxidation-reduction cycles has been observed by EC-STM. ${ }^{20-28}$ From in situ grazing incidence small-angle X-ray scattering (GISAXS) and EC-STM measurements of a $\mathrm{Pt}(111)$ electrode in perchloric acid, it was concluded that the formation Pt islands during oxidation-reduction cycles resembles the $3 \mathrm{D}$ growth behavior of $\mathrm{Pt}(111)$ during deposition and erosion in ultrahigh vacuum. ${ }^{27,29}$ More recently, an in situ AFM investigation of polycrystalline platinum during oxidation-reduction cycles in sulfuric acid revealed the formation of platinum nanoparticles. $^{30}$

In contrast to the many papers on $\mathrm{Pt}$ dissolution and surface roughening in acidic media, there are only a few reports about Pt electrodes subjected to potential cycling in alkaline media. ${ }^{11,12}$ Cherevko et al. showed that the onset of dissolution in alkaline electrolyte is slightly lower than in acidic solution and that the amount of $\mathrm{Pt}$ dissolved during cycling is comparable though somewhat higher in alkaline solution. ${ }^{14}$ Lopes et al. showed that $\mathrm{Pt}$ dissolution from a $\mathrm{Pt}(111)$ single crystal in $\mathrm{KOH}$ occurs after the formation of $\mathrm{Pt}-\mathrm{O}_{\mathrm{ad}}$ on the surface, as in $\mathrm{HClO}_{4}$, though the presence of lithium leads to less dissolution compared to a potassium-based electrolyte. They also observed a very significant effect of chloride in the electrolyte, which leads to platinum-chloride complexation in solution and a strongly enhanced dissolution. ${ }^{19}$

In this work, we employ in situ AFM to investigate the surface roughening of the Pt polycrystalline electrode during oxidation-reduction cycles in sodium hydroxide. Like in acidic electrolyte, ${ }^{30}$ we observe Pt redeposition on the surface during the negative-going scan, but the extent of redeposition is much less than that in sulfuric acid electrolyte, which we attribute to the complexation of $\mathrm{Pt}$ with hydroxide ions. By using a potential program with different positive- and negative-going sweep rates, we also find that the oxide reduction rate has a profound effect on the surface roughening. The addition of chloride has a minor effect on the blank cyclic voltammogram of $\mathrm{Pt}$ in alkaline medium, but it strongly hinders the redeposition of platinum ions due to the complexation between chloride and $\mathrm{Pt}$ and, thereby, reduces the surface roughening (though it enhances the dissolution, as mentioned above). Our results confirm the power of in situ AFM in investigating the interfacial processes on the Pt electrode under electrochemical conditions and provide more detailed insights into the nature of the effect of the electrolyte on the roughening of $\mathrm{Pt}$ electrodes during potential cycling.

\section{EXPERIMENTAL SECTION}

The in situ AFM experiments were carried out in a customized electrochemical AFM (EC-AFM) cell made of Kel-F. Prior to each experiment, the cell components were cleaned by immersing in piranha solution, boiling three times in Millipore Milli-Q water (resistivity, $18.2 \mathrm{M} \Omega \mathrm{cm}$ ), and finally blow drying in air. The Pt disk (99.99\%, MaTecK) was flame-annealed and quenched with Milli-Q water before assembling into the EC-AFM cell. A leakless $\mathrm{Ag} / \mathrm{AgCl}$ (3 $\mathrm{M} \mathrm{KCl}$ ) electrode (WPI) was used as the reference electrode; the counter electrode was a $\mathrm{Pt}$ wire $(99.9 \%, \mathrm{MaTecK})$. All of the potentials in this article are reported with respect to reversible hydrogen electrode (RHE). A potentiostat (Metrohm Autolab PGSTAT204) was coupled with the atomic force microscope (JPK NanoWizard 4) to control the electrochemical condition during the experiments. In addition to the cyclic voltammetry (CV) experiments with varying sweep rate, the asymmetric $\mathrm{CV}$ experiments (i.e., $\mathrm{CV}$ with different scan rates for the positive- and negative-going scans) were also performed. The AFM imaging rate was $1 \mathrm{~Hz}$ per line, and all of the images were obtained using tapping mode, taken at a potential in the $\mathrm{Pt}$ double-layer window, i.e., $0.5 \mathrm{~V}$. The electrolyte was prepared from $\mathrm{NaOH}$ (30\%, Merck Suprapur) and $\mathrm{NaCl}$ (99.99\%, Merck Suprapur) and was neither degassed nor refreshed during each experiment.

\section{RESULTS AND DISCUSSION}

In Situ AFM Imaging of the Pt Surface. Figure 1 shows the surface of the Pt electrode as imaged by AFM after 100
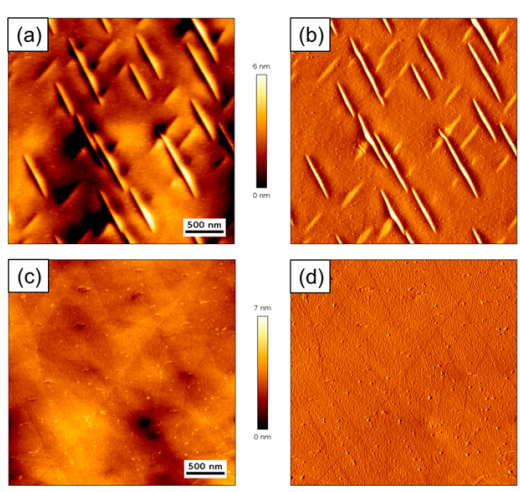

Figure 1. Topography of the Pt working electrode after potential cycling for 100 times between 0.05 and $2.0 \mathrm{~V}$ at scan rates of (a) 100 and (c) $10 \mathrm{mV} / \mathrm{s}$. (b, d) Error images that were simultaneously obtained with panels a and c, respectively.

oxidation-reduction cycles in $0.1 \mathrm{M} \mathrm{NaOH}$ between 0.05 and $2.0 \mathrm{~V}$ at two different scan rates (100 and $10 \mathrm{mV} / \mathrm{s})$. AFM images of the pristine $\mathrm{Pt}$ surface before cycling are provided in Figure S1 in the Supporting Information; the surface is not atomically flat and presents a dot-like topography when imaged in a $500 \times 500 \mathrm{~nm}^{2}$ range. The scar-like structures observed in Figure 1 are caused by the preparation in which the sample is heated to a high temperature and then quenched with water. The dark/light artifact around the scar-like features indicates that the feedback is not tracking these larger features optimally, but the feedback was optimized for the flatter areas and the data are not compromised by the feedback errors around the "large" scar-like features. The scar-like features are not related to any tip/scanner/microscope issue, as much smaller nanoparticles can be resolved easily. In addition, the microscope was used to measure HOPG both in air and in water, and we did not observe any abnormal features.

The formation of nanoparticles after cycling is observed on the surface as shown more clearly in the error images in Figure $1 \mathrm{~b}, \mathrm{~d}$. However, both the number and size of nanoparticles are much smaller than previously observed in sulfuric acid, even though the number of oxidation-reduction cycles was doubled compared to our previous work in acidic medium. ${ }^{30}$ From our previous work in sulfuric acid, we concluded that the formation of Pt nanoparticles takes place during the negative-going scan. The Pt that dissolves in the electrolyte acts as the source for the electrodeposition of the nanoparticles. According to the investigation by Topalov et al., who studied the influence of dissolved gases $\left(\mathrm{Ar}, \mathrm{H}_{2}, \mathrm{O}_{2}\right.$, and $\left.\mathrm{CO}\right)$ on $\mathrm{Pt}$ dissolution in 
$\mathrm{HClO}_{4}$, oxygen does not interfere with the dissolution process. ${ }^{16}$ The Pt nanoparticles that are formed in $0.1 \mathrm{M}$ $\mathrm{H}_{2} \mathrm{SO}_{4}$ are abundant and have a statistical mean size of $3.8 \mathrm{~nm}$ when the electrode is cycled in the potential window of $0.05-$ $2.0 \mathrm{~V}$, while the nanoparticles formed in $0.1 \mathrm{M} \mathrm{NaOH}$ have a size of less than $1.0 \mathrm{~nm}$. We note that, in principle, the $\mathrm{Pt}$ counter electrode may also serve as a source of platinum ions. However, the mass transport effects to be described in the next paragraph render this $\mathrm{Pt}$ a very unlikely source of the $\mathrm{Pt}$ nanoparticles on the working electrode.

The redeposition of Pt depends on the amount of dissolved $\mathrm{Pt}$ ions and their mass transport into the bulk of the electrolyte. Previous investigations of $\mathrm{Pt}$ dissolution in alkaline media showed that the amount of transiently dissolved $\mathrm{Pt}$ in base is more pronounced (though still in the same order of magnitude) than in acidic electrolyte. ${ }^{14,19,31}$ Moreover, by using the same scan rate, $100 \mathrm{mV} / \mathrm{s}$, the effect of the diffusion of $\mathrm{Pt}$ ions into the electrolyte should be similar in both alkaline and acidic conditions. However, the speciation of the dissolved Pt ions is different in alkaline solution in comparison to that in acid. Ion-exchange chromatography coupled to inductively coupled plasma mass spectrometry measurements has revealed that potential cycling of $\mathrm{Pt}$ in acidic solution up to $1.4 \mathrm{~V}$ generates $\mathrm{Pt}(\mathrm{II})$ oxide and results in both $\mathrm{Pt}(\mathrm{II})$ and $\mathrm{Pt}(\mathrm{IV})$ aqueous species in the solution, with about $80 \%$ of Pt being present as $\mathrm{Pt}(\mathrm{II}) .^{32}$ In alkaline solution, $\mathrm{Pt}$ ions can form complexes with $\mathrm{OH}^{-}$. Lopes et al. have indeed suggested that the alkaline electrolyte increases the amount of $\mathrm{Pt}$ dissolution in comparison to acidic media due to complexation of $\mathrm{Pt}$ ions with $\mathrm{OH}^{-19}$ It is indeed known that hydroxide complexes could contribute significantly to the solubility of $\mathrm{Pt}$ in aqueous solutions. ${ }^{33,34}$ The complex ion $\left[\mathrm{Pt}(\mathrm{OH})_{6}\right]^{2-}$ was found to be the major product of $\mathrm{Pt}$ dissolution in alkaline solution, ${ }^{35}$ which reduces to $\mathrm{Pt}$ metal at the hydrogen evolution region. ${ }^{36}$ We expect that the complexation between $\mathrm{Pt}$ ions with $\mathrm{OH}^{-}$ may then lead to a decrease of the rate of Pt redeposition. This lower redeposition rate may be part of the reason for the higher effective dissolution rate in alkaline media reported in the literature. ${ }^{14,19}$

Figure 1c shows an AFM image of the surface after oxidation-reduction cycles taken with a lower scan rate, 10 $\mathrm{mV} / \mathrm{s}$. The number of nanoparticles in the image is 190, which is less as compared to Figure 1a (430). In agreement with our previous work, ${ }^{30}$ using a lower scan rate reduces the extent of redeposition of $\mathrm{Pt}$. We ascribed this effect of the scan rate to the role of diffusion of dissolved Pt ions into the bulk of the electrolyte, which should be more significant at lower scan rate. As a result, less $\mathrm{Pt}$ is redeposited at low scan rate. A recent investigation by Lopes et al. studied the influence of varying the negative-going scan rate during cycling on the dissolution of Pt using online ICP-MS. ${ }^{37}$ With the positive-going scan rate fixed at $50 \mathrm{mV} / \mathrm{s}$, the amount of dissolved $\mathrm{Pt}$ from $\mathrm{Pt}(111)$ in $0.1 \mathrm{M} \mathrm{HClO}_{4}$ at the highest negative-going sweep rate, $500 \mathrm{~V} /$ $\mathrm{s}$, was found to be extremely low, which they attributed to the redeposition of Pt. They also concluded that redeposition of $\mathrm{Pt}$ during the negative-going scan is important in the mechanism of particle coarsening and surface roughening.

To test this explanation in alkaline solution, the positivegoing scan rate was set at $10 \mathrm{mV} / \mathrm{s}$ while the negative-going scan rate was varied between $10 \mathrm{mV} / \mathrm{s}$ and $100 \mathrm{~V} / \mathrm{s}$. Figure 2 shows the platinum electrode surface for a negative-going scan of $100 \mathrm{mV} / \mathrm{s}$, after 18 cycles (Figure 2a) and after 100 cycles (Figure $2 \mathrm{~b}$ ). The surface shows more nanoparticles than the

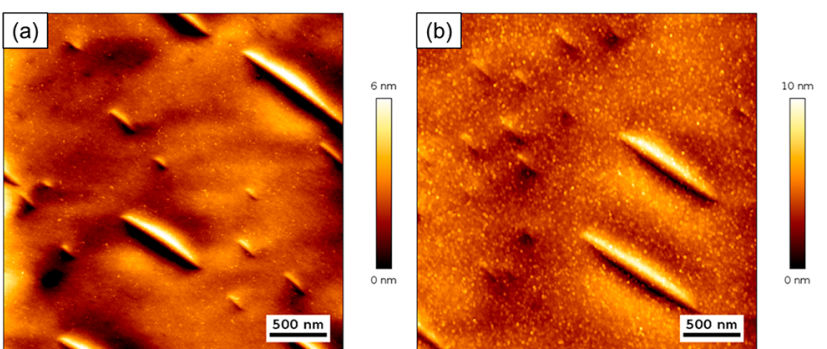

Figure 2. Topography of the Pt working electrode after potential cycling between 0.05 and $2.0 \mathrm{~V}$ with an asymmetric $\mathrm{CV}$, where the positive-going sweep rate is $10 \mathrm{mV} / \mathrm{s}$ and the negative-going sweep rate is $100 \mathrm{mV} / \mathrm{s}$. AFM images obtained after (a) 18 cycles and (b) 100 cycles.

surfaces shown in Figure 1. Nanoparticles with a height up to $1.4 \mathrm{~nm}$ were observed on the surface after 18 potential cycles. The nanoparticles cover the whole surface after 100 cycles with an increasing number and a bigger size, as illustrated in Figure $2 \mathrm{~b}$. With a higher negative-going scan rate, Pt ions do not have enough time to diffuse into the bulk of the electrolyte and therefore more $\mathrm{Pt}$ is deposited on the surface. This observation agrees with the model concluded for the roughening of $\mathrm{Pt}$ in sulfuric acid.

The effect of the asymmetric potential sweeps was further investigated by applying various negative-going scan rates from $10 \mathrm{mV} / \mathrm{s}$ to $100 \mathrm{~V} / \mathrm{s}$, while keeping the positive-going scan rate constant at $100 \mathrm{mV} / \mathrm{s}$. More Pt nanoparticles are formed on the Pt surface after 20 potential cycles between 0.05 and $2.0 \mathrm{~V}$ using a negative-going scan rate of $100 \mathrm{mV} / \mathrm{s}$ as compared to a scan rate of $10 \mathrm{mV} / \mathrm{s}$ (see Figure $\mathrm{S} 2$ in the Supporting Information), in agreement with Figure 2 and the conclusion about the importance of diffusion in the redeposition of platinum ions. However, the number of Pt nanoparticles does not monotonically increase with the higher negative-going scan rate, as shown in Figure 3. The AFM morphology images were treated by the edge detection function using the Sobel operator to enhance the surface features according to the manufacturer's instructions. There are only a few nanoparticles when using very fast negative-going scan rates, $100 \mathrm{~V} / \mathrm{s}$ (Figure S3a) and $10 \mathrm{~V} / \mathrm{s}$ (Figure $3 \mathrm{~b}$ ). More Pt nanoparticles are generated when decreasing the sweep rate to $1 \mathrm{~V} / \mathrm{s}$ (Figure 3c), and a large amount of nanoparticles is deposited on the surface after further decreasing the sweep rate to $100 \mathrm{mV} / \mathrm{s}$ (Figure 3d). In combination with Figure S2 this suggests that there is an optimal scan rate where the formation of $\mathrm{Pt}$ nanoparticles is highest.

The effect of the scan rate on surface roughening of $\mathrm{Pt}$ in alkaline media therefore indicates that there must be another slow process in the mechanism, which we consider to be the rate of $\mathrm{Pt}$ oxide reduction. Mom et al. reported that $\mathrm{Pt}$ nanoparticles revert to the metallic condition quickly after switching the potential from 1.85 to $0.05 \mathrm{~V}$ in $0.1 \mathrm{M} \mathrm{H}_{2} \mathrm{SO}_{4}$ electrolyte. $^{38}$ On the other hand, an operando ambient pressure X-ray photoelectron spectroscopy study of $\mathrm{Pt}$ in alkaline electrolyte reveals the accumulation of Pt oxide on the outmost surface of the electrode when returning to the doublelayer region after oxygen evolution reaction. ${ }^{39}$ Previous electrochemical work has also indicated that Pt oxides are reduced more slowly in alkaline media than in acidic media, attributed to the more anionic hydrous nature of the oxide films formed in alkaline media. ${ }^{40,41}$ We therefore conclude that 

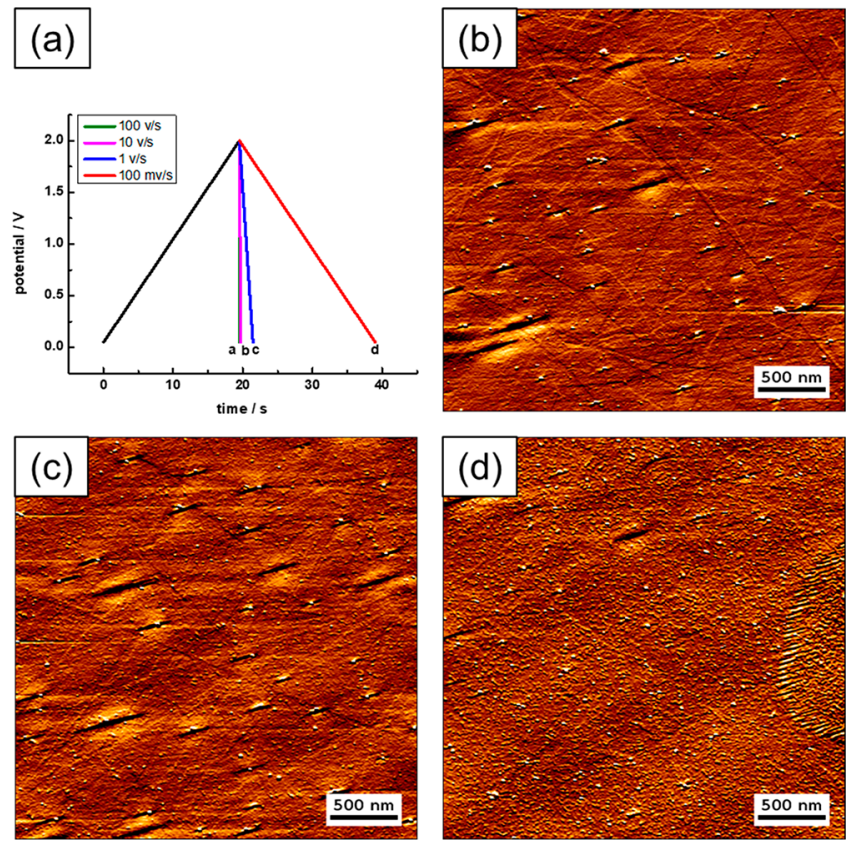

Figure 3. (a) Asymmetric cyclic voltammetry potential-time diagram for Pt disk electrode in $0.1 \mathrm{M} \mathrm{NaOH}$, where the positive-going scan rate is kept at $100 \mathrm{mV} / \mathrm{s}$ while the negative-going scan rate is varied from $100 \mathrm{mV} / \mathrm{s}$ to $100 \mathrm{~V} / \mathrm{s}$. AFM images of the Pt surface after applying 20 cycles of asymmetric sweeps with the negative-going sweep rates of (b) $10 \mathrm{~V} / \mathrm{s},(\mathrm{c}) 1 \mathrm{~V} / \mathrm{s}$, and (d) $100 \mathrm{mV} / \mathrm{s}$. All three images were morphology images treated with the edge detection function to enhance the edges of the features.

a key additional factor to be considered is the low reduction rate of Pt oxide for a planar electrode in alkaline solution. With a high sweep rate, greater than $1 \mathrm{~V} / \mathrm{s}$, the $\mathrm{Pt}$ oxide is accumulated rather than being reduced, leading to the formation of only a small amount of nanoparticles due to the lack of suitable (metallic) nucleation site for $\mathrm{Pt}$ redeposition. When the potential sweep rate is reduced, there is more time for the oxide reduction and $\mathrm{Pt}$ may redeposit on the metallic platinum during the negative-going scan. At the lowest scan rate, Pt ions generated during oxide reduction diffuse away from the surface, and $\mathrm{Pt}$ redeposition is less extensive. The assumption that reduction of $\mathrm{Pt}$ oxide is slow is also supported by a potential holding experiment, in which the potential is held at $2.0 \mathrm{~V}$ for $5 \mathrm{~min}$ at each cycle after positive-going sweep to the upper limit potential. Fewer nanoparticles can be observed by AFM (Figure S4b) in comparison to Figure 2a, even though more $\mathrm{Pt}$ oxide was formed by holding the potential at $2.0 \mathrm{~V}$.

We also have studied the influence of chloride in the electrolyte, as chloride is expected to enhance the dissolution of Pt by strong complexation with the dissolved Pt ions. Figure 4a presents the cyclic voltammograms that were obtained in the electrochemical AFM cell with different concentrations of chloride in $0.1 \mathrm{M} \mathrm{NaOH}$ (using $\mathrm{NaCl}$ as the chloride source). The CV curves are tilted due to residual oxygen in the electrolyte as we are using an open cell setup. The addition of chloride has only a small effect on the cyclic voltammogram of $\mathrm{Pt}$ in alkaline media, in agreement with previous literature. ${ }^{42}$ (The effect of chloride on the $\mathrm{Pt} \mathrm{CV}$ in acidic media is much bigger, due to specific adsorption of chloride on platinum in acidic media; see, e.g., the comparison between the CVs with a certain amount of chloride and the Pt blank $\mathrm{CV}^{43}$ ) The redox
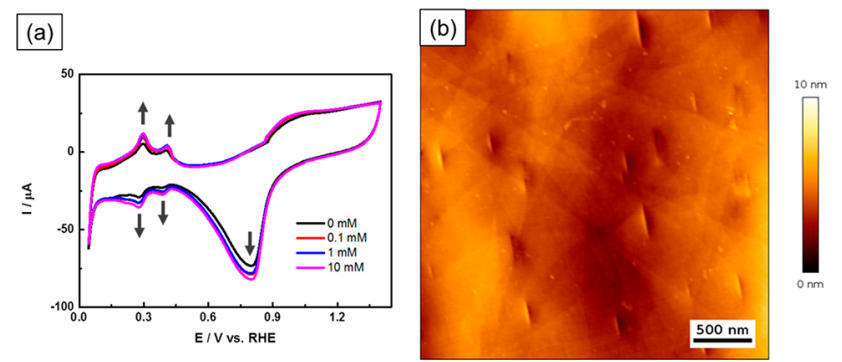

Figure 4. (a) Cyclic voltammograms recorded in the EC-AFM cell at a scan rate of $100 \mathrm{mV} / \mathrm{s}$. All curves show the 10th cycle. Electrolyte: $0.1 \mathrm{M} \mathrm{NaOH}+x \mathrm{mM} \mathrm{Cl}^{-}$. (b) Morphology of Pt surface after cycling for 100 times between 0.05 and $2.0 \mathrm{~V}$ with asymmetric $\mathrm{CV}$ in the chloride-containing electrolyte $0.1 \mathrm{M} \mathrm{NaOH}+0.1 \mathrm{mM} \mathrm{NaCl}$. The positive-going sweep rate is $10 \mathrm{mV} / \mathrm{s}$, and the negative-going sweep rate is $100 \mathrm{mV} / \mathrm{s}$.

peaks around 0.3 and $0.4 \mathrm{~V}$, attributed to the hydrogen underpotential deposition peaks of $\mathrm{Pt}$ in alkaline media, increase somewhat and the reduction peak at $0.8 \mathrm{~V}$ due to the reduction of $\mathrm{Pt}$ oxide that formed during the positive-going scan also increases somewhat in intensity when adding chloride to the electrolyte. However, the peak potentials do not change.

Even though addition of chloride has almost no effect on the cyclic voltammogram of $\mathrm{Pt}$, the presence of chloride prevents the redeposition of $\mathrm{Pt}$ ions due to the strong complexation between chloride and platinum. ${ }^{19,44}$ The morphology of the $\mathrm{Pt}$ surface was imaged by in situ AFM, as shown in Figure $4 \mathrm{~b}$. In contrast to the observations in Figure $3 b$, much fewer and smaller Pt nanoparticles, with a height up to $1 \mathrm{~nm}$, are randomly distributed on the surface. We conclude that the addition of only a small amount of chloride to the electrolyte (0.1 mM) does not yield any noteworthy changes in the electrochemical CV response of platinum but has a very significant effect on the corresponding surface morphology due to the complexation of the Pt ions. The stability constant of $\left[\mathrm{Pt}(\mathrm{OH})_{4}\right]^{2-}$ is $\log \beta_{4}=32$, while for the complex $\left[\mathrm{Pt}(\mathrm{Cl})_{4}\right]^{2-}$ the stability constant is 13.99 , which suggests a slightly lower complexation of $\mathrm{Pt}$ with $\mathrm{Cl}^{-}{ }^{45,46}$ Due to the lack of data about the stability of $\left[\mathrm{Pt}(\mathrm{OH})_{6}\right]^{2-}$, we cannot make a direct comparison between two $\mathrm{Pt}(\mathrm{IV})$ complexes. (The stability constant for $\left[\mathrm{Pt}(\mathrm{Cl})_{4}\right]^{2-}$ is $\left.33.9^{47}\right)$. Nevertheless, $\mathrm{H}_{2} \mathrm{Pt}(\mathrm{OH})_{6}$ and $\mathrm{H}_{2} \mathrm{Pt}(\mathrm{Cl})_{6}$ are both commercially available products. Thus, the $\mathrm{Pt}$ dissolving during oxide reduction complexes with the chloride ions, leading to a strong inhibition of the rate of $\mathrm{Pt}$ redeposition and a corresponding suppression of the Pt surface roughening. Bagotzky et al. also reported the enhancement of Pt dissolution in alkaline media by adding chloride to the electrolyte. $^{35}$

\section{CONCLUSION}

Here, we have used in situ AFM to investigate the formation of Pt nanoparticles on the surface of a polycrystalline flameannealed $\mathrm{Pt}$ electrode in $0.1 \mathrm{M} \mathrm{NaOH}$ during potential excursions between 0.05 and $2.0 \mathrm{~V}$. During the oxidationreduction cycles, the $\mathrm{Pt}$ electrode undergoes dissolution and redeposition repeatedly. The oxidation of $\mathrm{Pt}$ at positive potential forms an oxide layer on the surface. Partial dissolution of $\mathrm{Pt}$ occurs in the positive-going sweep, but the majority takes place during the negative-going scan. In the negative-going scan, reduction of the oxide leads to the formation of $\mathrm{Pt}$ ions close to the surface, which form a complex 
with $\mathrm{OH}^{-}$of the alkaline electrolyte. The complexation reduces the rate of redeposition of $\mathrm{Pt}$ as compared to the results in acidic solution. The redeposition can be further reduced by adding a trace of chloride to the electrolyte, again attributed to the strong complexation between chloride and Pt. Enhancement of the Pt nanoparticle formation can be achieved by selecting the positive-/negative-going scan rates separately. The redeposition of $\mathrm{Pt}$ depends on the formation of $\mathrm{Pt}$ oxide and the corresponding reduction as well as on the diffusion of the dissolved Pt ions into the bulk of the electrolyte. A smaller positive-going scan rate leads to a thicker Pt oxide, which acts as the precursor for the Pt ions. However, the rate of Pt oxide reduction in alkaline solution is slower than in acid solution, which means that at high scan rate less Pt oxide is reduced, and hence, fewer nanoparticles are formed on the surface. Our work shows the usefulness of in situ AFM measurements to provide a microscopic view of the Pt electrode surface under oxidation-reduction cycles, which helps to understand the dynamic changes of $\mathrm{Pt}$ under potential cycling conditions.

\section{ASSOCIATED CONTENT}

\section{S Supporting Information}

The Supporting Information is available free of charge at https://pubs.acs.org/doi/10.1021/acsaem.9b01700.

AFM images of the original Pt polycrystalline surface and the surface after applying oxidation-reduction cycles (PDF)

\section{AUTHOR INFORMATION}

\section{Corresponding Author}

*E-mail: m.koper@chem.leidenuniv.nl.

\section{ORCID $\odot$}

Marc T.M. Koper: 0000-0001-6777-4594

Notes

The authors declare no competing financial interest.

\section{ACKNOWLEDGMENTS}

This work received partial support by Hitachi, Ltd. and Hitachi High-Technologies Corp.

\section{REFERENCES}

(1) Shao-Horn, Y.; Sheng, W. C.; Chen, S.; Ferreira, P. J.; Holby, E. F.; Morgan, D. Instability of Supported Platinum Nanoparticles in Low-Temperature Fuel Cells. Top. Catal. 2007, 46, 285-305.

(2) Yu, X.; Ye, S. Recent advances in activity and durability enhancement of $\mathrm{Pt} / \mathrm{C}$ catalytic cathode in PEMFC: Part II: Degradation mechanism and durability enhancement of carbon supported platinum catalyst. J. Power Sources 2007, 172, 145-154.

(3) Debe, M. K. Electrocatalyst approaches and challenges for automotive fuel cells. Nature 2012, 486, 43-51.

(4) Jerkiewicz, G.; Vatankhah, G.; Lessard, J.; Soriaga, M. P.; Park, Y.-S. Surface-oxide growth at platinum electrodes in aqueous $\mathrm{H} 2 \mathrm{SO} 4$ : Reexamination of its mechanism through combined cyclic-voltammetry, electrochemical quartz-crystal nanobalance, and Auger electron spectroscopy measurements. Electrochim. Acta 2004, 49, 1451-1459.

(5) Conway, B. E. Electrochemical oxide film formation at noble metals as a surface-chemical process. Prog. Surf. Sci. 1995, 49, 331452.

(6) Tremiliosi-Filho, G.; Jerkiewicz, G.; Conway, B. E. Characterization and significance of the sequence of stages of oxide film formation at platinum generated by strong anodic polarization. Langmuir 1992, 8, 658-667.
(7) Xing, L.; Hossain, M. A.; Tian, M.; Beauchemin, D.; Adjemian, K. T.; Jerkiewicz, G. Platinum Electro-dissolution in Acidic Media upon Potential Cycling. Electrocatalysis 2014, 5, 96-112.

(8) Huang, Y. F.; Kooyman, P. J.; Koper, M. T. Intermediate stages of electrochemical oxidation of single-crystalline platinum revealed by in situ Raman spectroscopy. Nat. Commun. 2016, 7, 12440.

(9) Hanselman, S.; McCrum, I. T.; Rost, M. J.; Koper, M. T. M. Thermodynamics of the formation of surface $\mathrm{PtO}_{2}$ stripes on $\mathrm{Pt}(111)$ in the absence of subsurface oxygen. Phys. Chem. Chem. Phys. 2019, in press DOI: $10.1039 / \mathrm{C} 9 \mathrm{CP} 05107 \mathrm{D}$

(10) Drnec, J.; Harrington, D. A.; Magnussen, O. M. Electrooxidation of $\mathrm{Pt}(111)$ in acid solution. Curr. Op. Electrochem. 2017, 4, $69-75$.

(11) Visintin, A.; Canullo, J. C.; Triaca, W. E.; Arvia, A. J. Changes in real surface area, crystallographic orientation and morphology of platinum electrodes caused by periodic potential treatments: phenomenological approach. J. Electroanal. Chem. Interfacial Electrochem. 1988, 239, 67-89.

(12) Visintin, A.; Triaca, W. E.; Arvia, A. J. Changes in the surface morphology of platinum electrodes produced by the application of periodic potential treatments in alkaline solution. J. Electroanal. Chem. Interfacial Electrochem. 1990, 284, 465-480.

(13) Topalov, A. A.; Katsounaros, I.; Auinger, M.; Cherevko, S.; Meier, J. C.; Klemm, S. O.; Mayrhofer, K. J. J. Dissolution of Platinum: Limits for the Deployment of Electrochemical Energy Conversion? Angew. Chem., Int. Ed. 2012, 51, 12613-12615.

(14) Cherevko, S.; Zeradjanin, A. R.; Keeley, G. P.; Mayrhofer, K. J. J. A Comparative Study on Gold and Platinum Dissolution in Acidic and Alkaline Media. J. Electrochem. Soc. 2014, 161, H822-H830.

(15) Cherevko, S.; Zeradjanin, A. R.; Topalov, A. A.; Kulyk, N.; Katsounaros, I.; Mayrhofer, K. J. J. Dissolution of Noble Metals during Oxygen Evolution in Acidic Media. ChemCatChem 2014, 6, 2219-2223.

(16) Topalov, A. A.; Zeradjanin, A. R.; Cherevko, S.; Mayrhofer, K. $\mathrm{J}$. J. The impact of dissolved reactive gases on platinum dissolution in acidic media. Electrochem. Commun. 2014, 40, 49-53.

(17) Cherevko, S.; Topalov, A. A.; Zeradjanin, A. R.; Keeley, G. P.; Mayrhofer, K. J. J. Temperature-Dependent Dissolution of Polycrystalline Platinum in Sulfuric Acid Electrolyte. Electrocatalysis 2014, $5,235-240$.

(18) Topalov, A. A.; Cherevko, S.; Zeradjanin, A. R.; Meier, J. C.; Katsounaros, I.; Mayrhofer, K. J. J. Towards a comprehensive understanding of platinum dissolution in acidic media. Chem. Sci. 2014, 5, 631-638.

(19) Lopes, P. P.; Strmcnik, D.; Tripkovic, D.; Connell, J. G.; Stamenkovic, V.; Markovic, N. M. Relationships between Atomic Level Surface Structure and Stability/Activity of Platinum Surface Atoms in Aqueous Environments. ACS Catal. 2016, 6, 2536-2544.

(20) Sugawara, S.; Itaya, K. In situ scanning tunnelling microscopy of a platinum $\{111\}$ surface in aqueous sulphuric acid solution. $J$. Chem. Soc., Faraday Trans. 1 1989, 85, 1351-1356.

(21) Itaya, K.; Sugawara, S.; Sashikata, K.; Furuya, N. In situ scanning tunneling microscopy of platinum (111) surface with the observation of monatomic steps. J. Vac. Sci. Technol., A 1990, 8, 515519.

(22) Sashikata, K.; Furuya, N.; Itaya, K. In situ electrochemical scanning tunneling microscopy of single-crystal surfaces of $\mathrm{Pt}(111)$, $\mathrm{Rh}(111)$, and $\mathrm{Pd}(111)$ in aqueous sulfuric acid solution. J. Vac. Sci. Technol., B: Microelectron. Process. Phenom. 1991, 9, 457-464.

(23) Breuer, N.; Funtikov, A. M.; Stimming, U.; Vogel, R. In situ electrochemical STM imaging of roughened gold and platinum electrode surfaces. Surf. Sci. 1995, 335, 145-154.

(24) Furuya, N.; Shibata, M. Structural changes at various Pt single crystal surfaces with potential cycles in acidic and alkaline solutions. $J$. Electroanal. Chem. 1999, 467, 85-91.

(25) Furuya, N.; Ichinose, M.; Shibata, M. Structural changes at the $\mathrm{Pt}(100)$ surface with a great number of potential cycles. J. Electroanal. Chem. 1999, 460, 251-253. 
(26) Wakisaka, M.; Asizawa, S.; Uchida, H.; Watanabe, M. In situ STM observation of morphological changes of the $\mathrm{Pt}(111)$ electrode surface during potential cycling in $10 \mathrm{mM}$ HF solution. Phys. Chem. Chem. Phys. 2010, 12, 4184-4190.

(27) Ruge, M.; Drnec, J.; Rahn, B.; Reikowski, F.; Harrington, D. A.; Carlà, F.; Felici, R.; Stettner, J.; Magnussen, O. M. Structural Reorganization of $\mathrm{Pt}(111)$ Electrodes by Electrochemical Oxidation and Reduction. J. Am. Chem. Soc. 2017, 139, 4532-4539.

(28) Jacobse, L.; Huang, Y.-F.; Koper, M. T. M.; Rost, M. J. Correlation of surface site formation to nanoisland growth in the electrochemical roughening of $\mathrm{Pt}(111)$. Nat. Mater. 2018, 17, 277282.

(29) Rost, M. J.; Jacobse, L.; Koper, M. T. M. The dualism between adatom- and vacancy-based single crystal growth models. Nat. Commun. 2019, 10, 5233.

(30) Deng, X.; Galli, F.; Koper, M. T. M. In Situ Electrochemical AFM Imaging of a Pt Electrode in Sulfuric Acid under Potential Cycling Conditions. J. Am. Chem. Soc. 2018, 140, 13285-13291.

(31) Wang, Z.; Tada, E.; Nishikata, A. Communication-Platinum Dissolution in Alkaline Electrolytes. J. Electrochem. Soc. 2016, 163, C853-C855.

(32) Xing, L.; Jerkiewicz, G.; Beauchemin, D. Ion exchange chromatography coupled to inductively coupled plasma mass spectrometry for the study of Pt electro-dissolution. Anal. Chim. Acta 2013, 785, 16-21.

(33) Colombo, C.; Oates, C. J.; Monhemius, A. J.; Plant, J. A. Complexation of platinum, palladium and rhodium with inorganic ligands in the environment. Geochem.: Explor., Environ., Anal. 2008, 8, 91-101.

(34) Wood, S. A. Experimental determination of the hydrolysis constants of Pt2+ and $\mathrm{Pd} 2+$ at $25^{\circ} \mathrm{C}$ from the solubility of Pt and Pd in aqueous hydroxide solutions. Geochim. Cosmochim. Acta 1991, 55, 1759-1767.

(35) Bagotzky, V. S.; Khrushcheva, E. I.; Tarasevich, M. R.; Shumilova, N. A. Corrosion of platinum catalyst in alkaline solutions. J. Power Sources 1982, 8, 301-309.

(36) Burke, L. D.; Roche, M. B. C.; O’Leary, W. A. The role of hydrous oxide in the electrochemical behaviour of platinum. J. Appl. Electrochem. 1988, 18, 781-790.

(37) Lopes, P. P.; Tripkovic, D.; Martins, P. F. B. D.; Strmcnik, D.; Ticianelli, E. A.; Stamenkovic, V. R.; Markovic, N. M. Dynamics of electrochemical $\mathrm{Pt}$ dissolution at atomic and molecular levels. J. Electroanal. Chem. 2018, 819, 123-129.

(38) Mom, R.; Frevel, L.; Velasco-Vélez, J.-J.; Plodinec, M.; KnopGericke, A.; Schlögl, R. The Oxidation of Platinum under Wet Conditions Observed by Electrochemical X-ray Photoelectron Spectroscopy. J. Am. Chem. Soc. 2019, 141, 6537-6544.

(39) Favaro, M.; Valero-Vidal, C.; Eichhorn, J.; Toma, F. M.; Ross, P. N.; Yano, J.; Liu, Z.; Crumlin, E. J. Elucidating the alkaline oxygen evolution reaction mechanism on platinum. J. Mater. Chem. A 2017, 5, 11634-11643.

(40) Burke, L. D.; Murphy, M. M. Effect of solution $\mathrm{pH}$ on hydrous oxide growth and reduction on polycrystalline platinum. J. Electroanal. Chem. Interfacial Electrochem. 1991, 305, 301-312.

(41) Xia, S. J.; Birss, V. I. In situ mass and ellipsometric study of hydrous oxide film growth on $\mathrm{Pt}$ in alkaline solutions. Electrochim. Acta 2000, 45, 3659-3673.

(42) Pérez, M. C.; Rincón, A.; Gutiérrez, C. Effect of chloride ions on the electrooxidation at low potentials of dissolved carbon monoxide on platinum. J. Electroanal. Chem. 2001, 511, 39-45.

(43) Geiger, S.; Cherevko, S.; Mayrhofer, K. J. J. Dissolution of Platinum in Presence of Chloride Traces. Electrochim. Acta 2015, 179, 24-31.

(44) Aruguete, D. M.; Murayama, M.; Blakney, T.; Winkler, C. Enhanced release of palladium and platinum from catalytic converter materials exposed to ammonia and chloride bearing solutions. Environ. Sci. Process Impacts 2019, 21, 133-144.

(45) Wood, S. A.; Mountain, B. W.; Fenlon, B. J. Thermodynamic constraints on the solubility of platinum and palladium in hydro- thermal solutions: reassessment of hydroxide, bisulfide, and ammonia complexing. Econ. Geol. Bull. Soc. Econ. Geol. 1989, 84, 2020-2028.

(46) Elding, L. I. Stabilities of platinum(II) chloro and bromo complexes and kinetics for anation of the tetraaquaplatinum(II) ion by halides and thiocyanate. Inorg. Chim. Acta 1978, 28, 255-262.

(47) Kononova, O. N.; Duba, E. V.; Shnaider, N. I.; Pozdnyakov, I. A. Ion exchange extraction of platinum(IV) and palladium(II) from hydrochloric acid solutions. Russ. J. Appl. Chem. 2017, 90, 12391245. 